\title{
Stable and Dynamic Forms of Cytoskeletal Proteins in Slow Axonal Transport
}

\author{
Tomoko Tashiro and Yoshiaki Komiya \\ Department of Biochemistry, Institute of Brain Research, Tokyo University Faculty of Medicine, 7-3-1 Hongo, Bunkyo-ku, \\ Tokyo, 113 Japan
}

Dynamic organization of the axonal cytoskeleton was investigated by analyzing slow axonal transport of tubulin and other major cytoskeletal proteins in the motor axons of rat sciatic nerve 1-4 weeks after injection of L-35S-methionine into the anterior horn area of $L_{3}-L_{5}$ lumbar spinal cord.

A large proportion (50-65\%) of tubulin transported in the axon was found to be insoluble when extracted with $1 \%$ Triton at $4^{\circ} \mathrm{C}$. This cold-insoluble tubulin was also resistant to other microtubule-destabilizing agents such as $\mathrm{Ca}^{2+}$, colchicine, and nocodazole, suggesting that it corresponded to the stably polymerized tubulin speclfic to the axon. From the cold-soluble fraction, microtubules containing a distinct set of associated proteins were recovered by the taxol-dependent procedure.

Transport pattern of cold-soluble and -insoluble tubulin in this system showed a time-dependent broadening of the tubulin wave resulting in the appearance of a new faster wave enriched in cold-soluble tubulin. The slower and the faster waves of tubulin were defined as group $V$ or slow component a (SCa) and group IV or slow component b (SCb), respectively, with respect to the 2 subcomponents of slow transport originally described in the optic system. However, compositions of groups IV and $\mathbf{V}$ in sciatic motor axons differed significantly from those of the optic system.

Actin also exhibited a clear dual wave pattern of transport that coincided well with that of tubulin, indicating that both actin and tubulin were the major components of both groups IV and V. At 3 weeks postlabeling, when the 2 groups were fully separated, group $V$ contained $58 \%$ of total tubulin and $41 \%$ of total actin, while group IV contained $29 \%$ of tubulin and $\mathbf{4 3} \%$ of actin. Actin associated with group IV was highly enriched in the soluble population. Neurofilament proteins were confined to group $V$, which exhibited broadening similar to that of insoluble tubulin.

From these results it is proposed that the 2 rate components of slow axonal transport arise as a consequence of cytoskeletal proteins existing in 2 forms, stably polymerized and dynamic, which differ in their transport rates.

Received Jan. 25, 1988; revised Aug. 11, 1988; accepted Aug. 15, 1988

We wish to thank Dr. M. Suffness of the National Cancer Institute (Bethesda MD) for providing us with Taxol. This work was supported in part by research grants from the Ministry of Education, Science and Culture of Japan.

Correspondence should be addressed to Dr. Tomoko Tashiro at the above address.

Copyright (C 1989 Society for Neuroscience $0270-6474 / 89 / 030760-09 \$ 02.00 / 0$
A well-differentiated cytoskeleton composed of an extensively cross-linked network of neurofilaments and microtubules is characteristic of mature axons (Hirokawa, 1982; Tsukita et al., 1982). In recent ycars, immunohistochemical studies have largely contributed to the discovery of some of the molecular events leading to the organization of the axon-specific cytoskeleton, such as differential expression of microtubule-associated proteins (MAPs) (Binder et al., 1985; Riederer and Matus, 1985) and posttranslational phosphorylation of neurofilament proteins (Sternberger and Sternberger, 1983; Bennett and DiLullo, 1985). Pulse-labeling the cytoskeletal proteins by injecting radioactive precursors into the cell body region and following their subsequent axonal transport offers another possibility of observing dynamic interactions among these proteins in situ.

Mainly on the basis of studies on the retinal ganglion cell axons, 2 rate components are defined in the slow transport conveying cytoskeletal proteins (Lasek and Hoffman, 1976; Willard and Hulebak, 1977; Black and Lasek, 1980; Levine and Willard, 1980; Tytell et al., 1981), the slower one containing neurofilament proteins and tubulin (group $\mathrm{V}$ or SCa) and a slightly faster component containing actin together with some cytoplasmic proteins (group IV or $\mathrm{SCb}$ ). The 2 subcomponents have been suggested to represent the movement of 2 cytoskeletal networks: $\mathrm{SCa}$ that of the microtubule-neurofilament network and $\mathrm{SCb}$ that of the actin-based cytomatrix (Brady and Lasek, 1981; Garner and Lasek, 1982). Further studies on the systems, however, have revealed variations in rates and compositions, as well as relative amounts of groups IV (SCb) and V (SCa) (Mori et al., 1979; Tashiro and Komiya, 1983, 1987; Tashiro et al., 1984; McQuarrie et al., 1986; Oblinger et al., 1987). In the sensory fibers of the sciatic nerve (axons of the dorsal root ganglion cells: DRG axons), tubulin in the 2 rate components has been shown to differ in solubility as well (Tashiro et al., 1984; Tashiro and Komiya, 1987).

Furthermore, some of the transported tubulin shows peculiar insolubility under various conditions known to depolymerize cytoplasmic microtubules (Brady et al., 1984; Tashiro et al., 1984; Brady and Black, 1986; Tashiro and Komiya, 1987). Recently, a morphological correlate of stable tubulin has been described in mature axons as short fragments of cold-resistant microtubules, which in some cases amounts to $50 \%$ of axonal microtubules (Heidemann et al., 1984; Baas and Heidemann, 1986; Brady and Black, 1986; Donoso, 1986; Sahenk and Brady, 1987). The present study was undertaken to investigate how soluble and insoluble subpopulations of tubulin were related to the 2 rate components of slow axonal transport. Motor fibers of the sciatic nerve (axons of the anterior horn cells: AH axons) 
were chosen for relative homogeneity in fiber population, as well as long length to allow better separation of different components. When transported proteins were fractionated according to solubility in addition to rate of transport as described in the following, we found that tubulin and actin transported in groups IV and V differed significantly in their stability as polymers.

\section{Materials and Methods}

Radioactive labeling and axonal transport of cytoskeletal proteins in the motor fibers of the sciatic nerve. Male albino Wistar rats, 7 weeks old, were used throughout the experiment. Under ether anesthesia, $\mathrm{L}^{-35} \mathrm{~S}$ methionine (800-1400 Ci/mmol; New England Nuclear, Boston) concentrated by lyophilization $(25 \mu \mathrm{Ci}$ in $0.2 \mu \mathrm{l})$ was injected into the anterior horn area of $\mathrm{L}_{3}-\mathrm{L}_{5}$ spinal cord twice on each side. One to four weeks after injection, sciatic nerve and ventral root were dissected out, frozen on a plastic plate, and cut into $6 \mathrm{~mm}$ consecutive segments.

Fractionation of labeled tubulin into cold-soluble and-insoluble subpopulations. Labeled nerve segments obtained 4 weeks after isotope injection were frozen in liquid nitrogen and crushed to fine powder in a stainless steel mortar with a hammer operated by compressed air and were then homogenized in assembly buffer $(0.1 \mathrm{M}$ PIPES, pH $6.9,0.5$ $\mathrm{mm} \mathrm{MgCl}_{2}, 1 \mathrm{~mm}$ EGTA, $0.1 \mathrm{~mm}$ GTP) with or without $1 \%$ Triton $\mathrm{X}-100$. Proximal $1.2 \mathrm{~cm}$ ( 2 segments) of the root was excluded to avoid contamination from nonmigrating label. The extract was centrifuged at $100,000 \times g$ for $1 \mathrm{hr}$ at $4^{\circ} \mathrm{C}$ to yield supernatant and pellet fractions containing cold-soluble and cold-insoluble tubulin, respectively.

Microtubules were recovered from the cold-soluble fraction by taxoldependent procedure (Vallee, 1982). The supernatant fraction was treated with $0.3 \mathrm{~g} / \mathrm{ml}$ of Bio-beads SM-2 (Bio-Rad Laboratories, Richmond, CA) for $2 \mathrm{hr}$ at $4^{\circ} \mathrm{C}$ to remove most of Triton (Holloway, 1973). After removal of beads by filtration, taxol (a gift from Dr. M. Suffness of the National Cancer Institute, Bethesda, MD) and GTP were added to give final concentrations of $20 \mu \mathrm{M}$ and $1 \mathrm{~mm}$, respectively, and the filtrate was incubated at $37^{\circ} \mathrm{C}$ for $30 \mathrm{~min}$. Polymerized microtubules were recovered as a pellet after centrifugation at $100,000 \times \mathrm{g}$ for $30 \mathrm{~min}$ at $30^{\circ} \mathrm{C}$ through a cushion of $10 \%$ sucrose containing taxol.

To test the solubility of cold-insoluble tubulin under various microtubule-depolymerizing conditions, cold-insoluble precipitate was resuspended in $0.1 \mathrm{M}$ PIPES (pH 6.9) containing a $0.5 \mathrm{~mm} \mathrm{MgCl}$ and divided into 9 identical aliquots. To each aliquot, the following chemicals were added to give final concentrations as described; (1) $20 \mu \mathrm{M}$ methyl(5-[2-thienylcarbonyl]-1H-benzimidazoyl-2-yl) carbamate (Nocodazole; Sigma, St. Louis), $5 \mathrm{~mm}$ EGTA, (2) $10 \mu \mathrm{M}$ colchicine, $5 \mathrm{~mm}$ EGTA, (3) $2 \mathrm{~mm} \mathrm{CaCl}_{2}$, (4) 5 mм EGTA, (5) $0.75 \mathrm{м} \mathrm{NaCl}$, 5 mм EGTA, (6) 2 м urea, 5 mм EGTA, (7) 4 м urea, 5 mм EGTA, (8) $0.5 \% ~ N$-lauroylsarcosine, sodium salt (Sarkosyl), 5 mm EGTA, (9) 0.5\% Sarkosyl, $2 \mathrm{M}$ urea, $5 \mathrm{~mm}$ EGTA. After $30 \mathrm{~min}$ at $4^{\circ} \mathrm{C}$, samples were centrifuged at $100,000 \times g$ for $1 \mathrm{hr}$. Supernatant fractions were dialyzed against 5 mM EGTA and freeze-dried.

For SDS gel electrophoresis (Laemmli, 1970), each fraction was dissolved in SDS sample buffer containing 2\% SDS, $80 \mathrm{~mm}$ Tris (pH 6.8), $5 \mathrm{~mm} \beta$-mercaptoethanol, and $10 \%$ glycerol, and heated at $100^{\circ} \mathrm{C}$ for 3 min. For 2-dimensional electrophoresis (O’Farrell, 1975), samples were dissolved in lysis buffer containing $2 \%$ Nonidet P40, 9.5 м urea, $2 \%$ Ampholines (LKB, Sweden), and $0.5 \% \beta$-mercaptoethanol. The second dimension was $10 \%$ in acrylamide.

Transport patterns of cytoskeletal proteins in the soluble and insoluble fractions. For each time point (1-4 weeks after isotope injection), 2 or 3 nerves obtained from 1 or 2 animals were processed together. Each set of $6 \mathrm{~mm}$ nerve segments from identical positions was frozen in liquid nitrogen, crushed as described above, and homogenized in $2.5 \mathrm{ml}$ of Triton-buffer containing $1 \%$ Triton X-100, $50 \mathrm{~mm}$ Tris (pH 7.5), 25 $\mathrm{mm} \mathrm{KCl}, 1 \mathrm{~mm} \mathrm{MgCl} 2,5 \mathrm{~mm}$ EGTA, and $5 \mathrm{~mm} \beta$-mercaptoethanol. After standing at $4^{\circ} \mathrm{C}$ for $1 \mathrm{hr}$, the homogenate was layered onto a discontinuous sucrose density gradient comprised of 1 and $0.4 \mathrm{M}$ sucrose in Triton-buffer and centrifuged at $67,000 \times g$ for $2 \mathrm{hr}$. Supernatant (S) was treated with Bio-Beads SM-2 as described above, dialyzed against 5 mM EGTA, and lyophilized. Two bands on top and at the interface between the 2 sucrose layers were collected, diluted with Triton buffer, and centrifuged at $100,000 \times g$ for $1 \mathrm{hr}$ to yield a pellet (M). The cytoskeletal pellet $(\mathrm{P})$ was at the bottom of $1 \mathrm{~m}$ sucrose. The 3 fractions, $\mathrm{S}, \mathrm{M}$, and $\mathrm{P}$ were each dissolved in $400 \mu \mathrm{l}$ of SDS sample buffer, and aliquots were subjected to gel electrophoresis on $10 \%$ acrylamide gels.

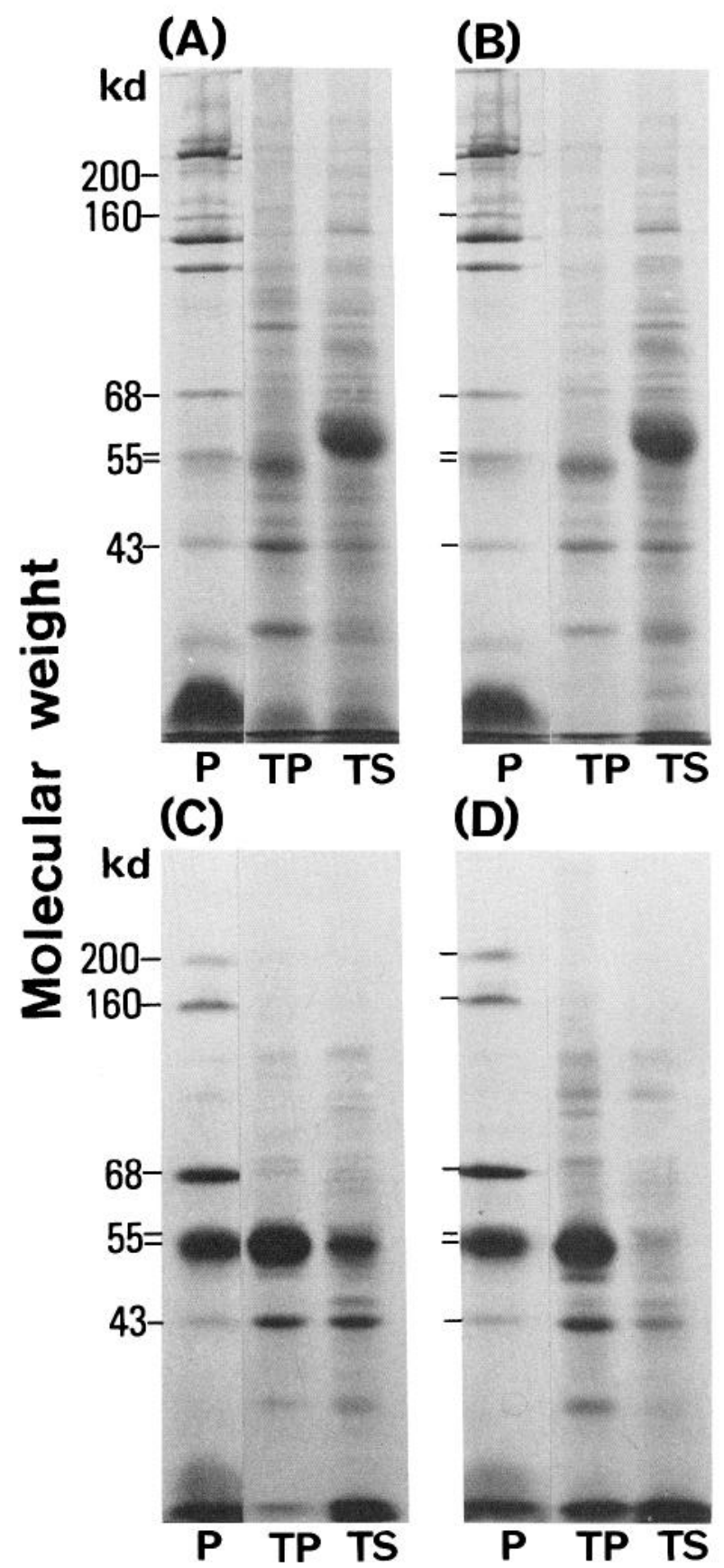

Figure 1. Cold extraction of transported cytoskeletal proteins from the nerve. Sciatic nerves obtained 4 weeks after injection of $\mathrm{L}^{-35} \mathrm{~S}-$ methionine into $\mathrm{L}_{3}-\mathrm{L}_{5}$ spinal cord were frozen, crushed to fine powder, and extracted with cold assembly buffer $(0.1 \mathrm{M}$ PIPES, pH $6.9,0.5 \mathrm{~mm}$ $\mathrm{MgCl}_{2}, 1 \mathrm{~mm}$ EGTA, $0.1 \mathrm{~mm}$ GTP) with $(B, D)$ or without $(A, C) 1 \%$ Triton X-100. Cold-insoluble fraction $(P)$ was separated from the soluble extract by centrifugation at $4^{\circ} \mathrm{C}$. In $B$ and $D$, soluble extract was treated with Bio-Beads SM-2 to remove most of Triton. Microtubule pellet $(T P)$ and supernatant $(T S)$ fractions were obtained from the soluble extract by taxol-dependent polymerization followed by centrifugation as described in Materials and Methods. $A$ and $B$, Acrylamide gels, $10 \%$, stained with Coomassie blue after electrophoresis. $C$ and $D$, Fluorograms of $A$ and $B$. Neurofilament proteins, tubulin, and actin are marked with their molecular weights.

Labeled proteins on the gel were visualized by fluorography (Bonner and Laskey, 1974).

For the measurement of radioactivity associated with individual cytoskeletal proteins, gels were stained with Coomassie Brilliant blue after 


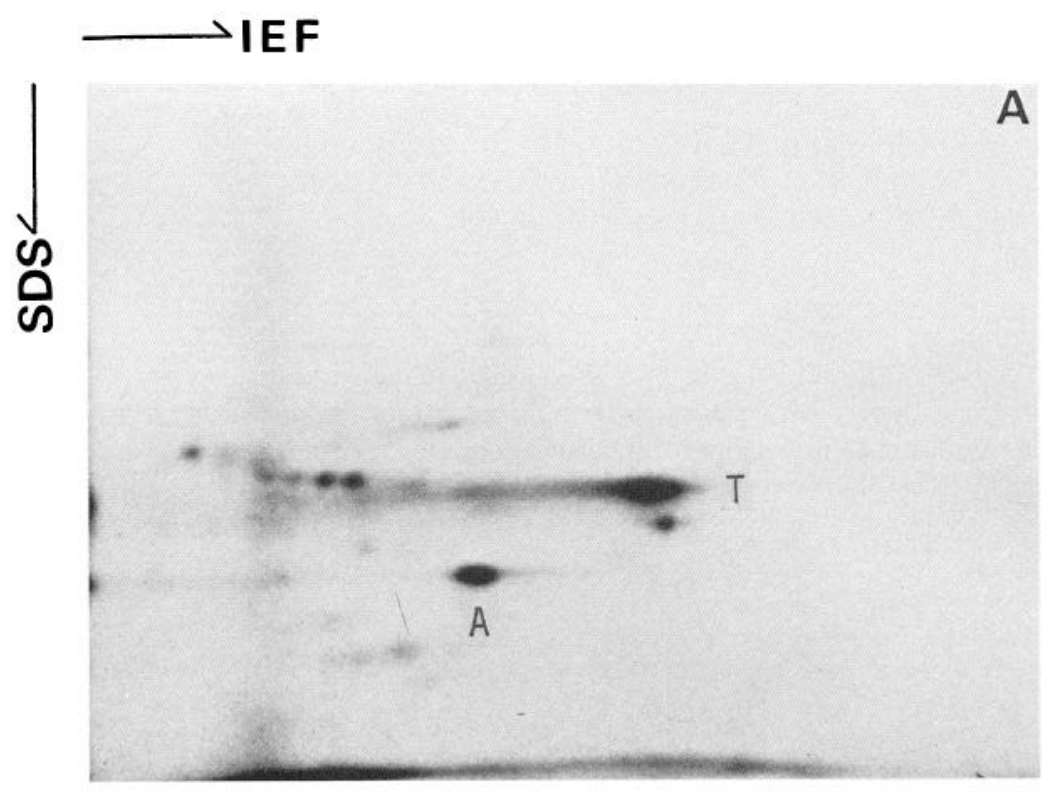

Figure 2. Two-dimensional electrophoretic comparison of taxol-microtubules recovered from the cold-soluble fraction with the cold-insoluble fraction. Sciatic nerves obtained 4 weeks after labeling the spinal cord with $\mathrm{L}^{-35} \mathrm{~S}$ methionine were extracted with $1 \%$ Triton at $4^{\circ} \mathrm{C}$ as described in Materials and Methods. Labeled proteins associated with microtubules recovered from the soluble extract by taxol-dependent polymerization $(A)$ were compared with those in the cold-Triton-insoluble fraction $(B)$ after 2-dimensional PAGE and fluorography. $A$, actin; $T$, tubulin; $N F-L$, smallest neurofilament subunit ( $68 \mathrm{kDa}) ; N F-M$, intermediate neurofilament subunit $(160 \mathrm{kDa})$.

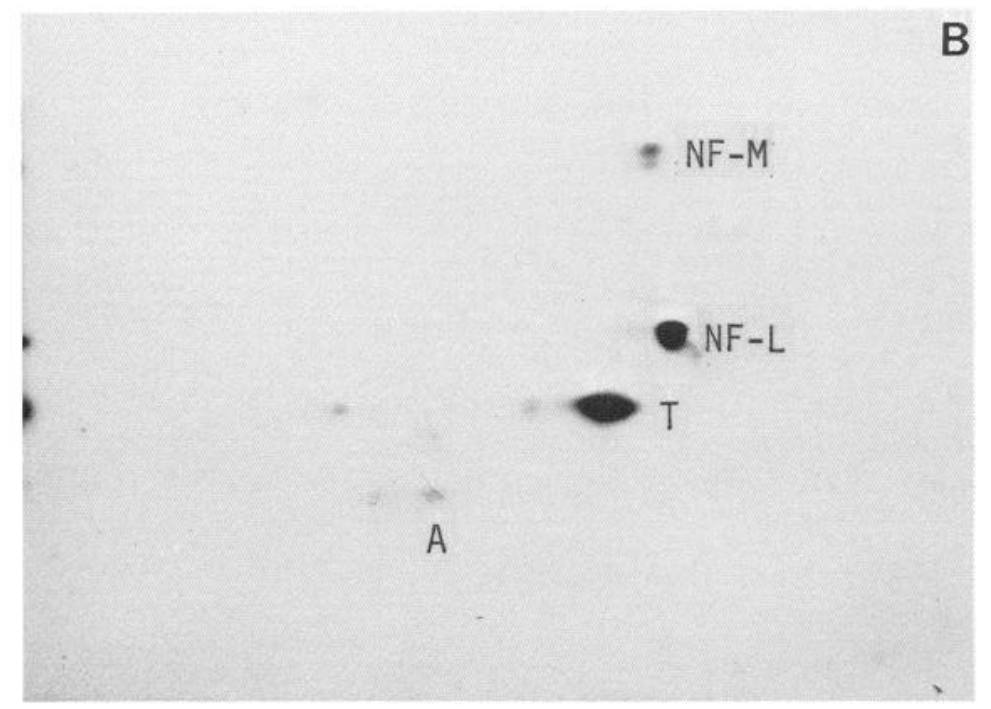

electrophoresis, and the bands corresponding to tubulin, actin, and 3 neurofilament subunits were cut out. Radioactivity in each gel piece was measured by liquid scintillation counting following overnight extraction at room temperature with $1 \mathrm{ml}$ of Soluene 350 (Packard Instrument Inc., Downers Grove, IL).

\section{Results}

\section{Cold-soluble and -insoluble tubulin in the axon}

To investigate the nature of axonal tubulin, sciatic nerves and ventral roots taken 4 weeks after injection of radioactive methionine into the lumbar spinal cord were used. At this time point, labeled cytoskeletal proteins had advanced well into the nerve. The first 2 segments that sometimes contained the nontransported labeled material due to leakage of the injected precursor were excluded. Effective extraction of axonal material was possible by crushing the frozen nerve segments to fine powder as described in Materials and Methods. Triton X-100 further facilitated the extraction of labeled material by $30-40 \%$.

Even after such an extensive cold extraction, $60 \%$ of radioactivity associated with the tubulin band on SDS gels remained insoluble (Fig. 1). This band was identified with tubulin on the 2-dimensional gel (Fig. 2B). Cold-soluble tubulin, which amounted to $40 \%$ of total tubulin, was quantitatively recovered by taxol-induced polymerization after removal of excess Triton as shown in Figures 1 and $2 A$. At this stage, detailed comparison of tubulin subunit compositions in the 2 fractions was not possible since other cytoskeletal proteins were contained in the coldinsoluble fraction. One of the major spots just below tubulin in Figure $2 A$ was not related to tubulin by peptide mapping analysis (data not shown).

A distinct set of proteins was consistently associated with taxol microtubules obtained from the cold-soluble fraction. These include polypeptides with molecular weights of $32,43,60,68$ 70,80 , and $100-110 \mathrm{kDa}$ (Figs. 1 and $2 A$ ). The $43 \mathrm{kDa}$ component was identified with actin on the 2-dimensional gel (Fig. $2 A$ ). None of these associated proteins was detected in the coldinsoluble fraction, which contained very few polypeptides besides tubulin, neurofilament proteins, and small amounts of actin (Fig. 2B).

More than $95 \%$ of the cold-insoluble tubulin was not only resistant to cold but to various other microtubule-depolymer- 
izing agents such as $\mathrm{Ca}^{2+}$, colchicine, and nocodazole as shown in Figure 3. Large amounts of tubulin were left unextracted with high concentrations of urea, which effectively solubilized the neurofilament proteins. Total solubilization of cold-insoluble tubulin was accomplished by the use of ionic detergents such as Sarkosyl. Tubulin solubilized with $0.5 \%$ Sarkosyl could be recovered by taxol-dependent polymerization (data not shown).

\section{Transport patterns of cold-soluble and -insoluble tubulin}

Transport patterns of cold-soluble and -insoluble tubulin were analyzed independently by separating the 2 populations contained in each $6 \mathrm{~mm}$ nerve segment on a step sucrose gradient $1-4$ weeks after labeling. Figure 4 shows an example of such a fractionation of axonally transported proteins 3 weeks after labeling. Cytoskeletal fraction $(\mathrm{P})$ obtained as a pellet through 1 M sucrose was enriched in the neurofilament proteins. Intermediate sucrose layer $(0.4 \mathrm{M})$ was included to avoid contamination of both supernatant $(\mathrm{S})$ and $\mathrm{P}$ fractions with large amounts of myelin. Two bands on top of 1 and $0.4 \mathrm{M}$ sucrose layers were collected to yield the myelin-rich fraction $(\mathrm{M})$, which contained large amounts of labeled tubulin with relatively less neurofilament proteins. Fraction $\mathrm{S}$ was devoid of neurofilament proteins except for some material corresponding to the largest subunit with molecular weight of $200 \mathrm{kDa}(\mathrm{NF}-\mathrm{H})$. The 3 fractions thus showed distinct protein compositions.

Radioactivity associated with tubulin in the 3 fractions was measured by cutting out the gel bands corresponding to tubulin at different time intervals after isotope injection. Since differences in the organization of tubulin in $\mathrm{P}$ and $\mathrm{M}$ fractions were unknown, tubulin-associated radioactivity in the two fractions was added together to give the amount of insoluble tubulin. Results are expressed in Figure 5 as the distribution of radioactivity along the nerve as a percentage of the total radioactivity. Results from 1 of the 3 series of experiments using 2 animals for each time point are presented in Figure 5. The results of other series were in good agreement with this series.

Focusing on the migration of cold-soluble tubulin (Fig. 5A), a time-dependent broadening of the tubulin wave resulting in the appearance of a new faster-migrating wave ahead of the main wave was evident. Though different in composition the main wave containing neurofilament proteins and actin as well as tubulin was defined as group $\mathrm{V}$, the slower of the 2 rate components described in slow axonal transport in the retinal ganglion cell axons (Willard and Hulebak, 1977; Black and Lasek, 1980; Levine and Willard, 1980; Tytell et al., 1981; Baitinger et al., 1982). The faster wave, accordingly, corresponded to group IV in this system. Cold-insoluble population also displayed broadening of the wave and the increase in the amount of radioactivity migrating ahead of group $\mathrm{V}$ with time (Fig. $5 B$ ). The leading edge of the tubulin wave at 1 and 2 weeks and the separated group IV wave at 3 and 4 weeks postlabeling (located at $54-84 \mathrm{~mm}$ from the spinal cord at 3 weeks and at $60-90 \mathrm{~mm}$

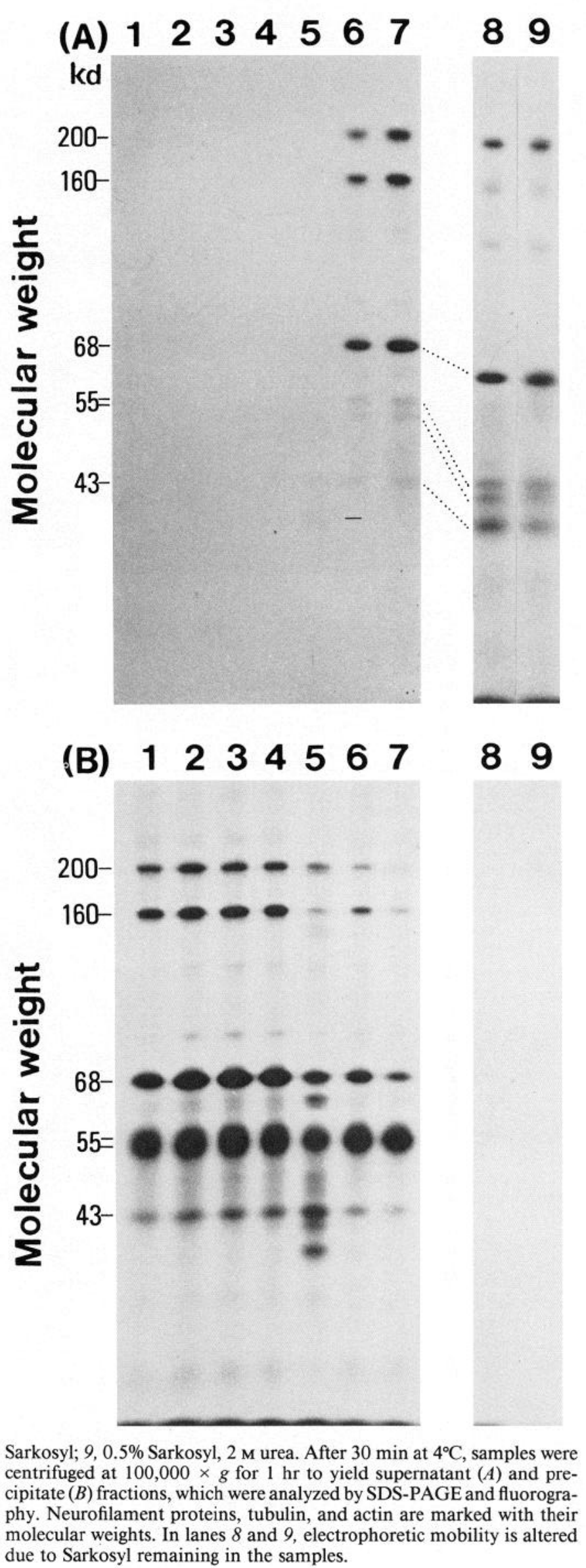

Sarkosyl; 9, 0.5\% Sarkosyl, $2 \mathrm{~m}$ urea. After $30 \mathrm{~min}$ at $4^{\circ} \mathrm{C}$, samples were centrifuged at $100,000 \times g$ for $1 \mathrm{hr}$ to yield supernatant $(A)$ and precipitate $(B)$ fractions, which were analyzed by SDS-PAGE and fluorography. Neurofilament proteins, tubulin, and actin are marked with their molecular weights. In lanes 8 and 9 , electrophoretic mobility is altered due to Sarkosyl remaining in the samples.
Figure 3. Solubility of cold-insoluble tubulin under various microtubule-destabilizing conditions. Cold-insoluble precipitate was prepared from sciatic nerves obtained 4 weeks postlabeling by extraction with $1 \%$ Triton at $4^{\circ} \mathrm{C}$, as described in Materials and Methods. The following chemicals were added to cold-insoluble precipitate resuspended in 0.1 M PIPES, pH 6.9, $0.5 \mathrm{~mm} \mathrm{MgCl}_{2}, 5 \mathrm{~mm}$ EGTA except for 3, where EGTA was omitted: $1,20 \mu \mathrm{M}$ nocodazole; $2,10 \mu \mathrm{M}$ colchicine; $3,2 \mathrm{~mm}$ $\mathrm{CaCl}_{2} ; 4$, no addition; $5,0.75 \mathrm{M} \mathrm{NaCl} ; 6,2 \mathrm{M}$ urea; $7,4 \mathrm{M}$ urea; $8,0.5 \%$ 


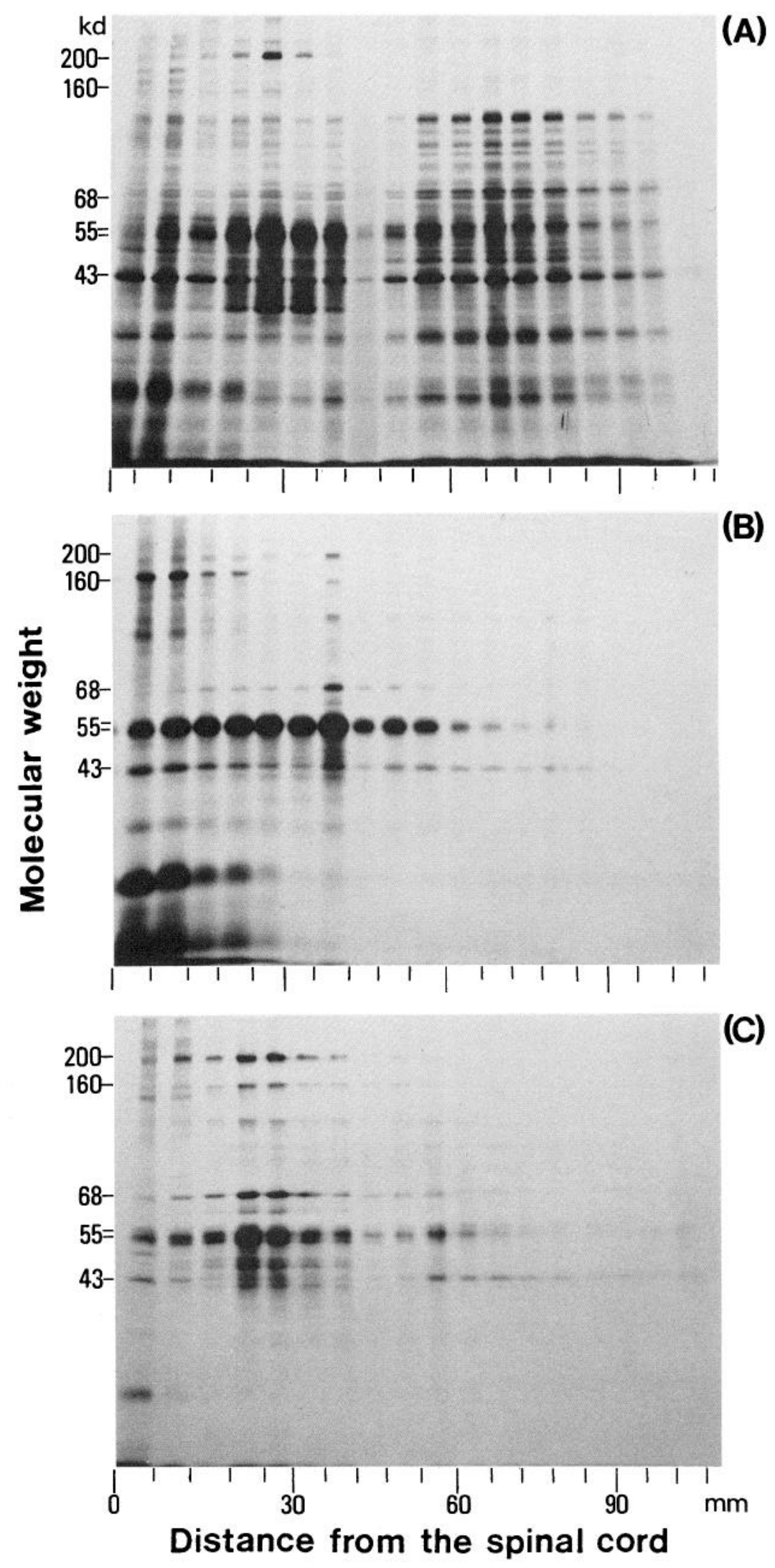

Figure 4. Fractionation of transported proteins in $6 \mathrm{~mm}$ consecutive segments of the sciatic nerve into supernatant $(S)$, myelin $(M)$, and cytoskeletal pellet $(P)$ fractions 3 weeks after labeling the spinal cord. Three of the sciatic nerves obtained 3 weeks after injection of $\mathrm{L}^{-35} \mathrm{~S}$-methionine into the spinal cord were cut into $6 \mathrm{~mm}$ consecutive segments. Each set of 3 segments from identical positions was frozen, crushed, homogenized in buffer containing $1 \%$ Triton and separated into $S, M$, and $P$ fractions by discontinuous sucrose density centrifugation as described in Materials and Methods. Each fraction was dissolved in $400 \mu \mathrm{l}$ of SDS sample buffer, of which $80 \mu \mathrm{l}$ was applied to the gel and electrophoresed. Labeled proteins in $\mathrm{S}(A), \mathrm{M}(B)$, and $\mathrm{P}(C)$ fractions were visualized by fluorography. Positions of neurofilament proteins, tubulin, and actin are marked with their molecular weights.

(A)

(B)

(C) 


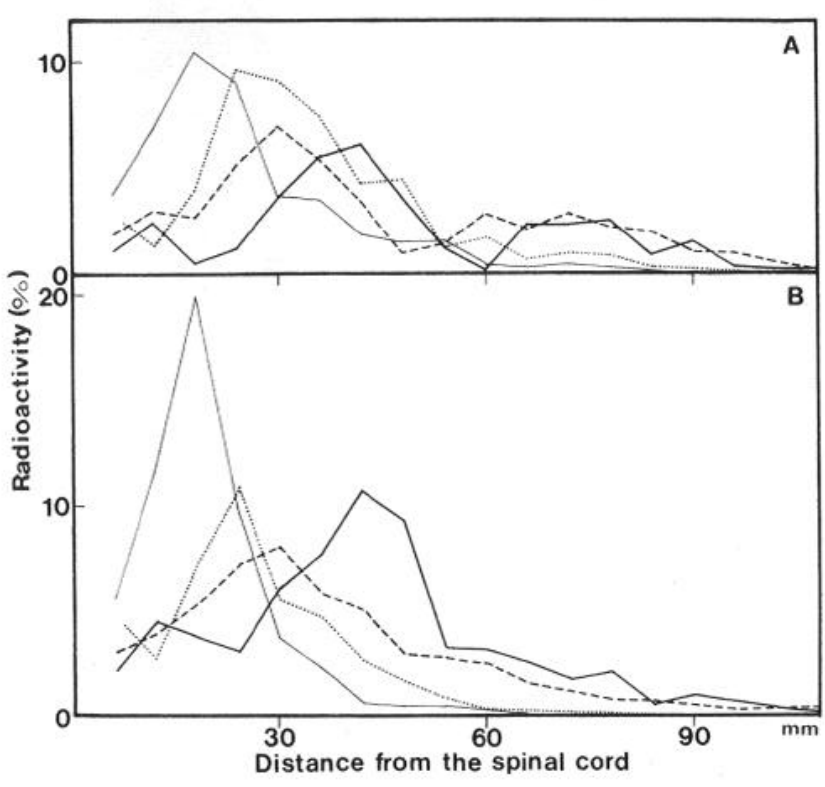

Figure 5. Transport kinetics of cold-soluble and cold-insoluble tubulin. Sciatic nerves were obtained $1-4$ weeks after labeling the spinal cord and cut into $6 \mathrm{~mm}$ consecutive segments. Two to three nerves were used for each time point. Each set of $6 \mathrm{~mm}$ nerve segments from identical positions was homogenized in buffer containing $1 \%$ Triton and separated into $\mathrm{S}, \mathrm{M}$, and $\mathrm{P}$ fractions by discontinuous sucrose density centrifugation as described in Materials and Methods. Each fraction was dissolved in $400 \mu \mathrm{l}$ of SDS sample buffer, of which $140 \mu \mathrm{l}$ was electrophoresed. For S and M fractions, cold cytoskeletal pellet prepared from rat spinal cord was run in the slots on both ends as standards. After staining with Coomassie blue, bands corresponding to tubulin were cut out. Radioactivity in each gel piece was extracted with Soluene 350 and measured by liquid scintillation counting. Radioactivity in fraction $\mathrm{S}(A)$ and sum of radioactivity in $\mathrm{M}$ and $\mathrm{P}$ fractions $(B)$ are expressed as the percentage of total tubulin-associated radioactivity 1 week (-), 2 weeks $(\cdots), 3$ weeks (-- $)$, and 4 weeks $(-)$ postlabeling.

at 4 weeks) were greatly enriched in the soluble population with soluble/insoluble ratio of 1.4-2.7. The group $\mathrm{V}$ wave, on the other hand, had a soluble/insoluble ratio of 0.5-0.9. At time points later than 4 weeks postlabeling, the group IV wave was in the branching portion of the nerve, and the migrating front started to exit from the observed length of the nerve, resulting in the decrease of total radioactivity associated with group IV.

\section{Transport patterns of other cytoskeletal components}

The distribution of other major axonal cytoskeletal proteins, actin and neurofilament proteins, between the soluble and insoluble fractions was similarly investigated at different time intervals after labeling.

At all time points analyzed (1-4 weeks), the migrating front of actin coincided well with that of tubulin. Compared with tubulin, a larger proportion of actin was found in the group IV, resulting in a more pronounced dual wave pattern of migration (Fig. 6). At 3 weeks postlabeling, $43 \%$ of total actin and $29 \%$ of total tubulin were associated with group IV, while in group V these values were $41 \%$ of actin and $58 \%$ of tubulin. Actin in groups IV and V had soluble/insoluble ratios of 2.9 and 1.5 , respectively, indicating that group IV was enriched in the soluble population of actin as well as tubulin. Altogether, $60-65 \%$ of actin was soluble at this time point.

In the case of neurofilament proteins, the soluble population was barely detectable except for some NF-H. Figure 7 shows

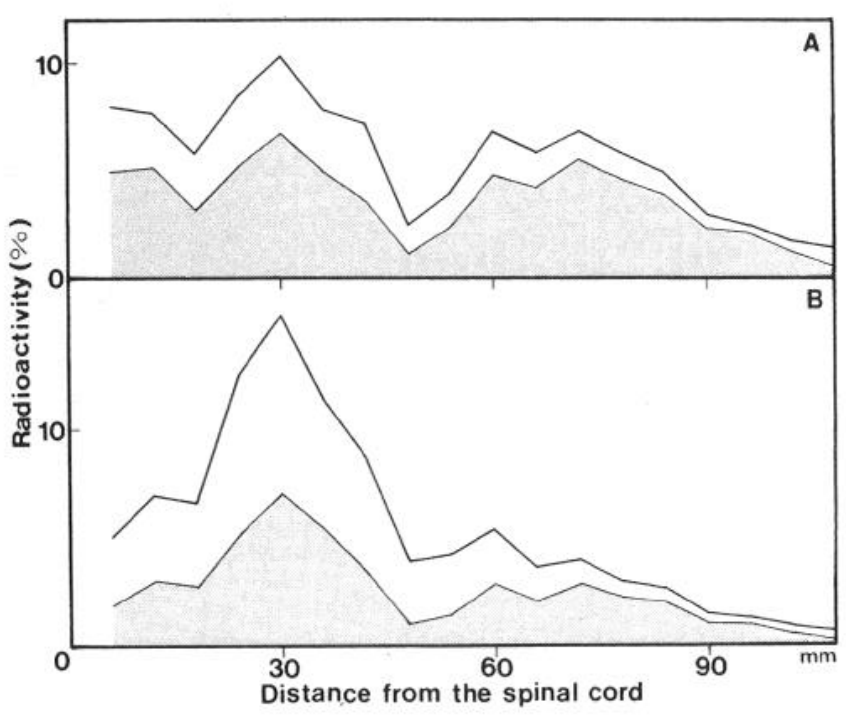

Figure 6. Transported actin and tubulin in the cold-soluble and coldinsoluble fractions of the sciatic nerve 3 weeks after labeling the spinal cord. Fractions $\mathrm{S}, \mathrm{M}$, and $\mathrm{P}$ were prepared from each set of $6 \mathrm{~mm}$ nerve segments obtained 3 weeks after labeling the spinal cord and electrophoresed as described in the legends to Figures 4 and 5 and in Materials and Methods. After staining with Coomassie blue, bands corresponding to actin and tubulin were cut out. Radioactivity associated with actin $(A)$ and tubulin $(B)$ in fraction $\mathrm{S}$ (shaded area) and in fractions $\mathrm{S}, \mathrm{M}$, and $\mathrm{P}$ (shaded area plus nonshaded area) is expressed as the percentage of total actin or tubulin radioactivity in the nerve respectively.

the transport pattern of the smallest subunit NF-L in the insoluble fraction, as a representative of those of the other 2 subunits. Group V wave of NF-L exhibited a pattern similar to the group $\mathrm{V}$ tubulin pattern with broadening of the wave also observed for insoluble tubulin.

\section{Discussion}

A large proportion of tubulin transported in the axon was found to be insoluble in $1 \%$ Triton at low temperature as well as in the presence of various microtubule-destabilizing agents (Figs. $1-3$ ), a property not shared by cytoplasmic microtubules in other cells (Brady et al., 1984; Brady and Black, 1986). The presence of such a stabilized population of tubulin has escaped much attention since it has been excluded from a commonly used brain microtubule preparation obtained by temperature-dependent polymerization (Shelanski et al., 1973). Only recently have morphological studies demonstrated short fragments of coldstable microtubules in mature axons (Heidemann et al., 1984; Baas and Heidemann, 1986; Donoso, 1986; Sahenk and Brady, 1987). Cold-stable microtubules are also known to occur in processes and neurites of cultured cells, which, however, do not seem to be as fully stabilized as those in mature axons (Black et al., 1984, 1986a). This unusual stability of axonal tubulin does not seem to arise solely from its interaction with neurofilaments as extraction of neurofilaments with urea did not effect its solubilization (Fig. 3). Thus, the insoluble tubulin defined experimentally in this study as that not solubilized with $1 \%$ Triton at low temperature constitutes a distinct subpopulation of tubulin polymer specific to mature axons. As neither centrosome nor other microtubule organizing centers are known in the axon, such stable polymers distributed along the axon may play an important role in the organization and maintenance of axonal microtubules. 


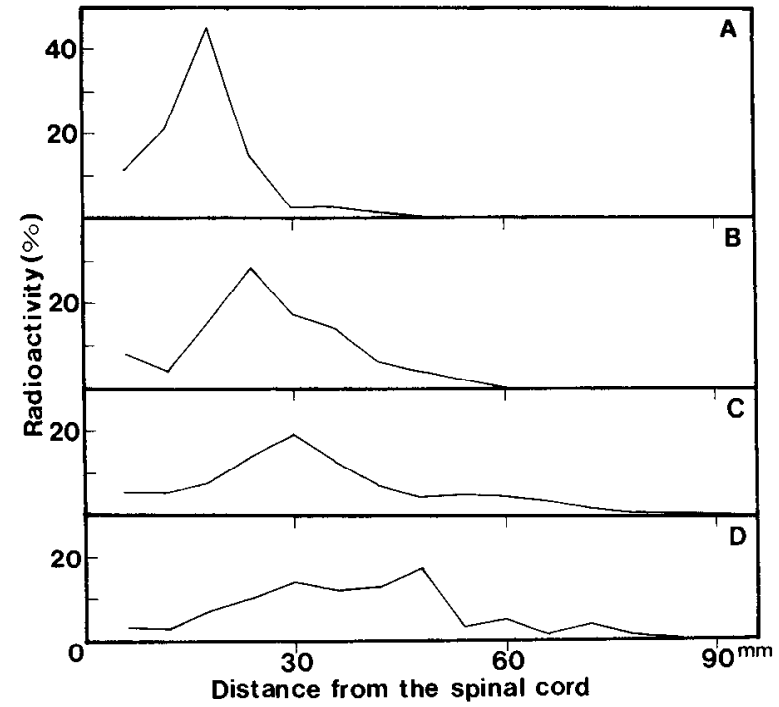

Figure 7. Transport kinetics of NF-L in the cold-soluble fraction. Radioactivity associated with NF-L in fractions $\mathrm{M}$ and $\mathrm{P}$ of each set of 6 mm segments from sciatic nerves obtained 1 week $(A), 2$ weeks $(B), 3$ weeks $(C)$, and 4 weeks $(D)$ after labeling the spinal cord were measured as described in the legends to Figures 4 and 5 and in Materials and Methods, and expressed as the percentage of total NF-L radioactivity in the nerve.

In this report, the presence of 2 waves in tubulin transport first described in our previous studies on DRG axons (Tashiro et al., 1984; Tashiro and Komiya, 1987) was confirmed in $\mathrm{AH}$ axons and further analyzed in relation to cold-soluble and -insoluble subpopulations of tubulin. In contrast to the clear dual wave pattern observed in DRG axons at 1 week postlabeling, a single wave of tubulin transported coordinately with neurofilament proteins was seen in $\mathrm{AH}$ axons at 1 week, later broadening and splitting into two (Fig. 5). The faster wave separating ahead of the main wave at later time points as well as the leading edge of the single tubulin wave at earlier time points were greatly enriched in cold-soluble tubulin, while insoluble tubulin was found mostly in the slower main wave, suggesting that tubulin in cold-soluble population separates from the main wave with time because of its higher rate of transport.

Although there are 2 rate components distinguishable in slow transport in DRG and $\mathrm{AH}$ axons, the compositions, relative amounts, and rates of these components are quite different from the 2 subcomponents of slow transport originally defined in the optic system. In the optic system, group $\mathrm{V}$ or $\mathrm{SCa}$ with the slowest rate consists of neurofilament proteins and tubulin, while a slightly faster group IV or SCb contains actin together with some cytoplasmic proteins (Willard and Hulebak, 1977; Black and Lasek, 1980; Levine and Willard, 1980; Tytell et al., 1981; Baitinger et al., 1982). This has led to the conclusion that SCa and $\mathrm{SCb}$ represent movement of the 2 cytoskeletal networks, the neurofilament-microtubule network and the microfilamentbased cytomatrix (Brady and Lasek, 1981; Garner and Lasek, 1982), respectively. However, in DRG and $\mathrm{AH}$ axons, as shown here and in previous reports, tubulin and actin are transported in both groups IV and V (Mori et al., 1979; Tashiro et al., 1984; McQuarrie et al., 1986; Oblinger et al., 1987; Tashiro and Komiya, 1987). In $\mathrm{AH}$ axons at 3 weeks postlabeling, when the 2 rate components are fully separated under our experimental conditions, $58 \%$ of tubulin and $41 \%$ of actin were found in group
$\mathrm{V}$, while $29 \%$ of tubulin and $43 \%$ of actin were in group IV. Furthermore, group IV is characterized by the presence of a higher proportion of cold-soluble tubulin and soluble actin compared with group $V$. This suggests the possibility that the 2 rate components arise as a result of partitioning cytoskeletal proteins that exist in 2 states, stably polymerized and dynamic, rather than as a representation of 2 discrete networks differing in composition, the cold-triton-soluble population represcnting the dynamic state may be the major transported form. This soluble population amounts to $42 \%$ of tubulin and $60 \%$ of actin in group $\mathrm{V}$, and $58 \%$ of tubulin and $74 \%$ of actin in group IV.

From several lines of evidence including coordinate transport of sets of cytoskeletal proteins (see above), rapid assembly after synthesis of cytoskeletal proteins in cultured neurons (Black et al., 1986b), and observation of fluorescently labeled tubulin within neurites of cultured cells (Keith, 1987), it has been proposed that cytoskeletal proteins move as assembled structural networks. In the case of microtubules, gliding movement of microtubules on glass surfaces in vitro (Allen et al., 1985; Vale et al., 1985) or against each other in lysed cell models (Koonce et al., 1987) have been demonstrated. However, within the intact axoplasm, where these structures are embedded in a highly crosslinked network (Hirokawa, 1982; Tsukita et al,. 1982), it is not certain that movement of long intact microtubules is favorablc. Developmental study (Willard and Simon, 1983) provides evidence that the emergence of NF-H, which serves as a crosslinker between neurofilaments and possibly also between neurofilaments and microtubules (Hirokawa et al., 1984), greatly reduces the rate of transport of group $\mathrm{V}$.

Another possibility that we consider here is that subunits or smaller soluble fragments of cytoskeletal polymers generated by local depolymerization are transported and added onto preexisting polymers. In case of axonal tubulin, the cold-insoluble population representing portions of microtubules stabilized in an axon-specific manner may serve as seeds for repolymerization of soluble dimers after movement through the axoplasm for a certain distance. Though axonal microtubules seem to be relatively stable compared with other cytoplasmic microtubules that exhibit "dynamic instability" exchanging rapidly with dimers (Mitchison and Kirschner, 1984), it is highly probable that exchange occurs at slower rates in the axon. It is well established that axonal microtubules have their fast-growing ends distal to the cell body (Heidemann et al., 1981), as is the case in flagella or cilia, which are known to grow by the addition of tubulin dimers onto the distal tip of the elongating microtubule (Rosenbaum et al., 1975). In growing axons, the growth cone has becn suggested to be a major site of assembly of microtubules (Bamburg et al., 1986). Similar mechanism can be postulated for axonal transport of actin which also exists as an equilibrium mixture of monomers and polymers.

Such a local exchange mechanism may not seem as appropriate for neurofilaments since a soluble form of neurofilament proteins is not known. In contrast to the optic axons where neurofilament proteins are transported in a symmetrical wave without significant broadening, group $\mathrm{V}$ wave of neurofilament proteins in $\mathrm{AH}$ axons becomes broadened and skewed towards the migrating front with time (Fig. 7). Though a possibility that bimodal size distribution of $\mathrm{AH}$ axons may contribute to wave deformation cannot be excluded, such a broadening may also be an indication of the appearance of a faster-migrating form when these proteins travel much longer distances at higher rates as in $\mathrm{AH}$ axons. We have shown previously that in DRG axons, 
a small but significant group IV wave of neurofilament proteins is detectable when labeled with radioactive phosphate instead of methionine (Komiya et al., 1986b). Recently, solubility of vimentin filaments, another type of intermediate filament that have also been considered highly insoluble, is shown to be regulated by phosphorylation (Inagaki et al., 1987). We have also demonstrated that phosphorylation and dephosphorylation of neurofilament proteins takes place locally during their transit in the axon (Komiya et al., 1986a).

In summary, further characterization of slow axonal transport was possible by fractionating the transported proteins according to their solubility in addition to their rates of transport. The faster of the 2 rate components-group IV, or $\mathrm{SCb}$-consisted mainly of cold-soluble tubulin and soluble actin, while group $\mathrm{V}$, or $\mathrm{SCa}$, was enriched in the insoluble forms of these proteins, suggesting the possibility that the 2 rate components arise from the presence of cytoskeletal proteins in 2 states rather than in 2 discrete networks. Such an approach may be useful in explaining variations of transport patterns observed in different systems and in analyzing changes in slow axonal transport during axonal regeneration or during development and aging.

\section{References}

Allen, R. D., D. G. Weiss, J. H. Hayden, D. T. Brown, H. Fujiwake, and M. Simpson (1985) Gliding movement of and bidirectional transport along single native microtubules from squid axoplasm: Evidence for an active role of microtubules in cytoplasmic transport. J. Cell Biol. 100: 1736-1752.

Baas, P. W., and S. R. Heidemann (1986) Microtubule reassembly from nucleating fragments during the regrowth of amputated neurites. J. Cell Biol. 103: 917-927.

Baitinger, C., J. Levine, T. Lorenz, C. Simon, P. Skene, and M. Willard (1982) Characteristics of axonally transported proteins. In Axoplasmic Transport, D. G. Weiss, ed., pp. 110-120, Springer-Verlag, Berlin.

Bamburg, J. R., D. Bray, and K. Chapman (1986) Assembly of microtubules at the tip of growing axons. Nature 321: 788-790.

Bennet, G. S., and C. DiLullo (1985) Slow posttranslational modification of a neurofilament protein. J. Cell Biol. 100: 1799-1804.

Binder, L. I., A. Frankfurter, and L. I. Rebhun (1985) The distribution of tau in the mammalian central nervous system. J. Cell Biol. 101: 1371-1378.

Black, M. M., and R. J. Lasek (1980) Slow components of axonal transport: Two cytoskeletal networks. J. Cell Biol. 86: 616-623.

Black, M. M., J. M. Cochran, and J. T. Kurdyla (1984) Solubility properties of neuronal tubulin: Evidence for labile and stable microtubules. Brain Res. 295: 255-263.

Black, M. M., J. M. Aletta, and L. A. Greene (1986a) Regulation of microtubule composition and stability during nerve growth factorpromoted neurite outgrowth. J. Cell Biol. 103: 545-557.

Black, M. M., P. Keyser, and E. Sobel (1986b) Interval between the synthesis and assembly of cytoskeletal proteins in cultured neurons. J. Neurosci. 6: 1004-1012.

Bonner, W. M., and R. A. Laskey (1974) A film detection method for tritium-labelled proteins and nucleic acids in polyacrylamide gels. Eur. J. Biochem. 46: 83-88.

Brady, S. T., and M. M. Black (1986) Axonal transport of microtubule proteins: Cytotypic variation of tubulin and MAPs in neurons. Ann. NY Acad. Sci. 466: 199-217.

Brady, S. T., and R. J. Lasek (1981) Nerve-specific enolase and creatine phosphokinase in axonal transport: Soluble proteins and the axoplasmic matrix. Cell 23: 515-523.

Brady, S. T., M. Tytell, and R. J. Lasek (1984) Axonal tubulin and axonal microtubules: Biochemical evidence for cold stability. J. Cell Biol. 99: 1716-1724.

Donoso, J. A. (1986) Microtubule stability along mammalian peripheral nerves. J. Neurobiol. 17: 383-403.

Garner, J. A., and R. J. Lasek (1982) Cohesive axonal transport of the slow component $\mathrm{b}$ complex of polypeptides. J. Neurosci. 2: 18241835.
Heidemann, S. R., J. M. Landers, and M. A. Hamborg (1981) Polarity orientation of axonal microtubules. J. Cell Biol. 91: 661-665.

Heidemann, S. R., M. A. Hamborg, S. J. Thomas, B. Song, S. Lindley, and D. Chu (1984) Spatial organization of axonal microtubules. J. Cell Biol. 99: 1289-1295.

Hirokawa, N. (1982) Cross-linker system between neurofilaments, microtubules, and membrane organelles in frog axons revealed by the quick-freeze, deep-etching method. J. Cell Biol. 94: 129-142.

Ilirokawa, N., M. A. Glicksman, and M. B. Willard (1984) Organization of mammalian neurofilament polypeptides within the neuronal cytoskeleton. J. Cell Biol. 98: 1523-1536.

Holloway, P. W. (1973) A simple procedure for removal of Triton $\mathrm{X}-100$ from protein samples. Anal. Biochem. 53: 304-308.

Inagaki, M., Y. Nishi, K. Nishizawa, M. Matsuyama, and C. Sato (1987) Site-specific phosphorylation induces disassembly of vimentin filaments in vitro. Nature 328: 649-652.

Keith, C. H. (1987) Slow transport of tubulin in the neurites of differentiated PC1 2 cells. Science 235: 337-339.

Komiya, Y., T. Tashiro, and M. Kurokawa (1986a) Phosphorylation of neurofilament proteins during their axonal transport. Biomed. Res. 7: 345-348.

Komiya, Y., T. Tashiro, and M. Kurokawa (1986b) Occurrence of faster migrating neurofilament proteins as revealed by their phosphorylation. Biomed. Res. 7: 359-363.

Koonce, M. P., J. Tong, U. Euteneur, and M. Schliwa (1987) Active sliding between cytoplasmic microtubules. Nature 328: 737-739.

Laemmli, U. K. (1970) Cleavage of structural proteins during the assembly of the head of bacteriophage T4. Nature 227: 680-685.

Lasek, R. J., and P. N. Hoffman (1976) The neuronal cytoskeleton, axonal transport and axonal growth. In Cell Motility, R. Goldman, T. Pollard, and J. Rosenbaum, eds., pp. 1021-1049, Cold Spring Harbor Laboratory, New York.

Levine, J., and M. Willard (1980) The composition and organization of axonally transported proteins in the retinal ganglion cells of the guinea pig. Brain Res. 194: 137-154.

McQuarrie, I. G., S. T. Brady, and R. J. Lasek (1986) Diversity in the axonal transport of structural proteins: Major differences between optic and spinal axons in the rat. J. Neurosci. 6: 1593-1605.

Mitchison, T., and M. Kirschner (1984) Dynamic instability of microtubule growth. Nature 312: 237-242.

Mori, H., Y. Komiya, and M. Kurokawa (1979) Slowly migrating axonal polypeptides. Inequalities in their rate and amount of transport between two branches of bifurcating axons. J. Cell Biol. 82: 174-184.

Oblinger, M. M., S. T. Brady, I. G. McQuarrie, and R. J. Lasek (1987) Cytotypic differences in the protein composition of axonally transported cytoskeleton in mammalian neurons. J. Neurosci. 7: 453-462.

O'Farrell, P. H. (1975) High resolution two-dimensional electrophoresis of proteins. J. Biol. Chem. 250: 4007-4021.

Riederer, B., and A. Matus (1985) Differential expression of distinct microtubule-associated proteins during brain development. Proc. Natl. Acad. Sci. USA 82: 6006-6009.

Rosenbaum, J. L., L. I. Binder, S. Granett, W. L. Dentler, W. Snell, R. Sloboda, and L. Haimo (1975) Directionality and rate of assembly of chick brain tubulin onto pieces of neurotubules, flagellar axonemes and basal bodies. Ann. NY Acad. Sci. 253: 147-177.

Sahenk, Z., and S. T. Brady (1987) Axonal tubulin and microtubules: Morphologic evidence for stable regions on axonal microtubules. Cell Motil. Cytoskel. 8: 155-164.

Shelanski, M. L., F. Gaskin, and C. R. Cantor (1973) Microtubule assembly in the absence of added nucleotides. Proc. Natl. Acad. Sci. USA 70: 765-768.

Sternberger, L. A., and N. H. Sternberger (1983) Monoclonal antibodies distinguish phosphorylated and nonphosphorylated forms of neurofilaments in situ. Proc. Natl. Acad. Sci. USA 73: 6126-6130.

Tashiro, T., and Y. Komiya (1983) Subunit composition specific to axonally transported tubulin. Neuroscience 9: 943-950.

Tashiro, T., and Y. Komiya (1987) Organization of cytoskeletal proteins transported in the axon. In Axonal Transport, R. S. Smith and M. A. Bisby, eds., pp. 201-221, Liss, New York.

Tashiro, T., M. Kurokawa, and Y. Komiya (1984) Two populations of axonally transported tubulin differentiated by their interactions with neurofilaments. J. Neurochem. 43: 1220-1225.

Tsukita, S., J. Usukura, S. Tsukita, and H. Ishikawa (1982) The cytoskeleton in myelinated axons: A freeze-etch replica study. Neuroscience $7: 2135-2147$. 
Tytell, M., M. M. Black, J. A. Garner, and R. J. Lasek (1981) Axonal transport: Each major rate component reflects the movement of distinct macromolecular complexes. Science 214: 179-181.

Vale, R. D., B. J. Schnapp, T. S. Recse, and M. P. Sheetz (1985) Organelle, bead, and microtubule translocations promoted by soluble factors from the squid giant axon. Cell 40: 559-569.

Vallee, R. B. (1982) A taxol-dependent procedure for the isolation of microtubules and microtubule-associated proteins (MAPs). J. Cell Biol. 92: 435-442.
Willard, M. B., and K. L. Hulebak (1977) The intra-axonal transport of polypeptide H: Evidence for a fifth (very slow) group of transported proteins in the retinal ganglion cells of the rabbit. Brain Res. 136: 289-306.

Willard, M., and C.Simon (1983) Modulation of neurofilament axonal transport during the development of rabbit retinal ganglion cells. Cell 35: 551-559. 